entre as categorias é de outro tipo, é uma relação de produção, não de verificação.

Desde a tese lacaniana de juventude da "psicanálise como método de verdade" até os últimos desdobramentos sobre a varidade (combinação de verdade e variedade) e desde o modelo elíptico das relações entre saber e verdade até a dialética fraturada da reabsorção da verdade ao saber até o sinthome como este laço entre heterogêneos (o traço sem fé da verdade) dizer que não há metalinguagem é dizer que não há linguagem objeto.

Em Lacan, não há confiança em categorias como tipos lógicos, classes de linguagens, universos de discurso, estratos de linguagem, língua denotativa, língua-objeto, linguagem semanticamente fechada (Tarski). Todas elas correspondem a decisões normativas infiltradas e revestidas de formalismo. Ou seja, a crítica da metalinguagem é um capítulo da valorização psicanalítica dos paradoxos de autorreferência não apenas uma estratégia de fundamentação. Aqui, o juízo de Iannini aponta novamente para a ontologia negativa: o que engendra paradoxos não é qualquer tipo de autorreferência, mas a tentativa de expressar conceitos formais através de funções proposicionais.

Esta é a tradução conceitual de máximas tais como: a verdade não-toda, o semi-dizer da verdade, a verdade em estrutura de ficção. Um princípio geral se depreende deste extenso e detalhado trabalho de pesquisa: o próprio discurso deve ser consistente, em sua maneira de dizer, com aquilo que diz. Há sim, uma ligação inextricável entre 0 que se diz, como se diz e sobre o que se diz. Esta solidariedade entre concepção de linguagem teorizada e praticada por Lacan não é nem a linguagem séria esperada do honnête-homme, nem uma ética discursiva ao modo de Habermas, nem mesmo uma moral terminológica como em Ogden e Richards, muito menos uma terapia linguística.

Contra a boa hipótese desenvolvida por Richard Simanke, de que em Lacan há uma concepção metafórica de teoria, Iannini problematiza e separa a metáfora surrealista da metáfora lacaniana. Separando a metáfora como processo que vai do simbólico ao Real da ficção como trajeto que vai do real ao simbólico, a ficção se alinha com o impossível enquanto a metáfora se alinha ao contingente.

Em suma, o leitor tem diante de si um ótimo exemplo do que a tradição brasileira de estudos lacanianos tem de melhor: cruzamento de perspectivas, combinação de fontes, mistura entre exegese e crítica, tensão entre clínica e política, presença e disseminação da possibilidade de pensar para além da reprodução metodológica de formas pré-constituídas.

Recebido em 20/8/2012.

Aprovado em 30/8/2012.

Christian Ingo Lenz Dunker

chrisdunker@usp.br

\section{A PSICANÁLISE É CONTRA-HEGEMÔNICA}

\section{Leituras da clínica, escritas da cultura, de Maria Cristina Poli, Campinas, Mercado de Letras, 2012, $192 \mathrm{p}$.}

\footnotetext{
Amadeu de Oliveira Weinmann

Professor do Departamento de Psicanálise e Psicopatologia do Instituto de Psicologia/ UFRGS.
}

Há vários motivos para saudar o lançamento de Leituras da clínica, escritas da cultura, de Maria Cristina Poli. A autora 
possui a habilidade incomum de posicionar-se de forma enviesada em determinado domínio de estudos para, a partir dessa perspectiva, problematizá-lo de um modo original. Ademais, tal peculiaridade envolve inclusive seu referencial teórico: a psicanálise de Freud e Lacan. Na análise do que formula como pergunta, a teoria psicanalítica sempre surge reinventada. E isso graças ao esforço permanente da autora no sentido de não permanecer confinada nos marcos da teoria que orienta sua pesquisa. Por meio do diálogo com a filosofia contemporânea, de incursões pelas artes plásticas e da interlocução com a literatura, Poli convoca-nos a incorporar sua postura crítica às políticas de reiteração identitária.

Alguns fios tecem a trama de Leituras da clínica, escritas da cultura. Um deles é o postulado da experiência analítica como estratégia de resistência. A autora parte da tese benjaminiana da indissociabilidade entre civilização e barbárie, a fim de problematizar um dos eixos constitutivos da Modernidade. Em tal configuração cultural, a experiência cede lugar à vivência, $\mathrm{O}$ que implica o declínio da transmissão do saber. E essa transformação é concomitante à passagem da tradição oral para a escrita. Algo relativo à assunção de uma posição de enunciação é perdido nessa mutação cultural. No entanto, se as formas modernas de escrita — como a imprensa e o romance - tendem a elidir o sujeito, é porque se inscrevem no ato cartesiano que funda a ciência moderna. A partir dele, é o experimento - o acúmulo ilimitado de conhecimento, por meio de um método que se pretende universal - , e não o saber singular e parcial da experiência, o que define a relação do sujeito com a verdade.

Assim, Poli retoma as formulações de Agamben, em Infância e história. A in-fância (do latim: não falante) consiste na condição humana primordial, da qual um sujeito precisa retirar-se, a fim de que uma enunciação seja possível. Tal concepção rompe a circularidade entre ser e pensamento, decorrente do cogito cartesiano. Dito de outro modo, supõe que a inscrição no logos não está dada de partida, mas deve ser conquistada. Porém, as condições vigentes na Modernidade colocam barreiras, por vezes intransponíveis, à enunciação de um sujeito - e não é preciso evocar o totalitarismo nazista para demonstrá-lo, basta escutar a psicopatologia da vida cotidiana. É nesse sentido que o ethos psicanalítico opera como estratégia de resistência, na medida em que oferece a possibilidade de que algo da ordem do traumático, isto é, dos efeitos da barbárie imanente ao processo civilizatório, possa ser compartilhado e, assim, converter-se em experiência.

É com esse mesmo fio que Cristina Poli enlaça a contemporaneidade. De acordo com a autora, a loquacidade midiática satura-nos com imagens visuais e sonoras, de modo a elidir a potência subversiva do silêncio - intervalo psíquico compartilhado, em que a elaboração do que há de incontornável na existência pode tornar-se experiência. No entanto, tal experiência não decorre de uma disposição do eu. Ela brota nos interstícios, nas fissuras entre o que nos acomete e sua nomeação. É precisamente quando nos arrancamos de um inescapável mutismo que algo da ordem da experiência pode formar-se. Em Lacan, essa palavra é dita plena, em contraposição à tagarelice pueril da fala midiática.

Outro fio importante, que costura distintos capítulos do livro, é o problema da pesquisa psicanalítica na universidade, isto é, de suas tensas relações com o paradigma científico ali hegemônico. Neste modelo epistemológico, o sujeito 
é mutilado naquilo que o singulariza. No que concerne ao sujeito do conhecimento, este deve ser abstrato, universal. No que tange ao objeto de conhecimento, já está dito: não lhe resta outra posição senão a de objeto. A condição de sua fala é de que esta lhe tenha sido previamente usurpada. No domínio biomédico, que exerce forte influência sobre o campo da psicologia, interessa pesquisar a vida nua, ou seja, o vivo na medida em que desprovido de valor simbólico. No limite, temos o ideal da psicopatologia do sistema DSM de que as tecnologias do olhar médico dispensem a equivocidade da palavra do paciente.

Em contrapartida, na pesquisa psicanalítica o sujeito epistêmico é, não por uma falha em sua constituição, mas em decorrência de seu próprio processo de formação, desejante. E isso de que ele se ocupa não é uma realidade objetiva, dele apartada, mas algo de inominável com o que ele se implica e que o convoca a pensar. Além disso, a pesquisa psicanalítica enlaça o Outro, por meio dessa estrutura ternária, que é a transferência. Por esses motivos, dela decorre não um acúmulo de conhecimentos supostamente universais, mas a elaboração de um saber singular. Depreende-se desses enunciados que a condição de possibilidade do aparecimento da psicanálise no campo dos saberes modernos é o cogito cartesiano. Entretanto, a filiação da invenção freudiana à operação fundante da ciência moderna é bastarda. É entre seus restos, ou seja, em meio ao que lhe é, simultaneamente, efeito e pura exterioridade, que floresce a pesquisa psicanalítica.

Assinalada essa distinção epistemológica crucial, Poli interroga-se: por que sustentar a pesquisa psicanalítica na universidade? Afinal, as associações psicanalíticas não promovem atividades de reflexão conceitual e de formação de novos analistas? A autora postula que a presença da psicanálise na universidade consiste em uma abertura para a alteridade. O estranhamento suscitado pela pesquisa psicanalítica no ambiente acadêmico retorna sobre ela como exigência de rigor metodológico e de depuração conceitual. E isso tem efeitos nas próprias associações psicanalíticas. Porém, tal posição ética de Cristina Poli independe das relações da psicanálise com a universidade. Para ela, sem a inscrição de um terceiro — dito de outro modo, sem a dissolução das filiações imaginárias — não há reinvenção da teoria psicanalítica, mas criação de uma religião laica. E isso alude a outra das condições da irrupção da psicanálise na Modernidade: a morte de Deus, isto é, a perda do referente absoluto, que assegurava o enlace perfeito entre as palavras e as coisas, por meio dos liames da representação.

Mais um fio, que perpassa a trama de Leituras da clínica, escritas da cultura, é o problema das formas da sexuação na atualidade. Inspirada nas análises freudianas da obra de Leonardo da Vinci, Poli procura pensar os modos contemporâneos de enlace entre criação artística e disposição pulsional, isto é, as representações que nos damos do corpo sexuado. A autora sugere que a atual estetização da vida cotidiana implica uma erótica que talvez não se organize mais, predominantemente, em torno do referente fálico. Em um amplo espectro da arte contemporânea, não se trata de produzir o efeito de engano do trompe l'oeil, que alude a uma posição fetichista, mas de constituir simulacros, que remetem ao gozo incessante de corpos imagéticos. Nessa perspectiva, a representação contemporânea do corpo sexuado aproxima-se do travestismo, se o entendermos não como uma máscara que encobre uma identidade problemática (masculina ou feminina), mas como uma 
posição sexuada definida pelo travestimento.

Tal proposição deixa como resto uma pergunta: o sexual admite apenas duas posições enunciativas? Em outras palavras, anatomia é destino? Prudente, Poli observa que o saber acerca do sexual sempre esbarra em algo da ordem do impossível. Dito de outro modo, em psicanálise, a disposição constitucional está longe de deter a verdade do sexo. No entanto, em Freud é possível encontrar certa ambiguidade em torno do termo falo. Algumas vezes, ele designa o pênis; outras, sua representação psíquica. Disso decorrem duas posições sexuadas, organizadas em torno do ter ou não o falo: a masculina e a feminina. Porém, as elaborações freudianas posteriores à formulação do conceito 'pulsão de morte' apontam para algo na feminilidade irredutível à referência fálica. É a partir desse ponto que Lacan desdobra suas reflexões acerca do gozo, no que este tem de inapreensível pelo discurso. Tal conceito permite o deslocamento da abordagem do sexual do significante fálico para a letra pulsional - marca no corpo feita pelo Outro, ponto de convergência entre significante e gozo. É a partir deste ponto, que um sujeito pode enunciar-se no campo erótico. Cristina Poli sustenta que essa teorização lacaniana é correlata de uma importante transformação cultural: a proliferação das posições discursivas no que concerne ao sexual.

Por fim, outro fio que compõe a teia de Leituras da clínica, escritas da cultura é o relativo à escrita da feminilidade na obra de Clarice Lispector. O gozo feminino inscreve-se? Inspirada em Lacan, Poli sugere que o texto clariciano consiste em lituraterra, ou seja, em algo que se produz na borda entre o simbólico e o real, ali onde floresce a letra, litoral vertiginoso, em cujas falésias cai o sujeito. Angústia.
Em última análise, o que uma mulher transmite é um pedaço de real. G. H. diante do olhar da barata, a fêmea totêmica. A busca do neutro, do inexpressivo, do inumano. A secreção branca, antes de ser dita leite materno ou massa da barata. Escrita do excesso, não da falta. Pode a feminilidade expressar-se de outro modo que não seja convulsionando essa estrutura falocêntrica que é a linguagem?

Entrelaçando esses fios, é possível cartografar a tessitura de Leituras da clínica, escritas da cultura. É sempre de fora que se exerce a crítica. Porém, entendase esse 'fora' como um lugar ainda não nomeado e a 'crítica' como o ato que o instaura como posição reflexiva. É dessa ordem a operação analítica, de acordo com Maria Cristina Poli. Como observa Edson Sousa, no prefácio do livro: ainda que a psicanálise tenha sido constantemente incorporada pelos discursos hegemônicos das ciências humanas e das artes - e, por essa via, associada aos modos de subjetivação dominantes na contemporaneidade —, seu lócus é a margem, a periferia, e seu destino é balançar o instituído, é abrir outras possibilidades de ser. Tal é o efeito do encontro com Leituras da clínica, escritas da cultura.

Recebida em 10/11/2012.

Aprovada em 25/11/2012.

Amadeu de Oliveira Weinmann weinmann.amadeu@gmail.com 